\title{
EFFECT OF IRRIGATION WATER QUALITY ON EMITTER'S CLOGGING PERCENT
}

\section{${ }^{(1)}$ Aboamera, M. A., \\ ${ }^{(1)}$ Gomaa, A. H. and \\ (2) Ibrahim, K. A. \\ ABSTRACT}

Drip irrigation systems have reached to a high level of technology, but still faced a remarkable operational problem named emitter clogging. Emitter clogging can affected distribution uniformity and the system performance, which has direct relationship with water quality. Three types of emitters (pressure compensating, long path and turbo-key) with nominal discharges 4, 6 and $8 \mathrm{~L} / \mathrm{h}$, respectively were tested under three types of irrigation water (Nile, Drainage and Fertilized water). Each test was carried out under four levels of operating pressure (75, 100, 125, $150 \mathrm{kPa}$ ). Emitter spacing was $50 \mathrm{~cm}$ and six laterals of $16 \mathrm{~mm}$ diameter and lateral spacing of $75 \mathrm{~cm}$ and $10 \mathrm{~m}$ long was used for each treatment. Drip irrigation system was constructed in Agricultural Engineering Department; faculty of agriculture; Menoufia University during 2015. The main objective was to evaluate emitter clogging percent and it's changing with operating periods for each treatment. The results showed that turbo key emitter achieved the lowest percent of clogging with Nile water (8.12\%) after 181 hours of operating period; at $100 \mathrm{kPa}$ of operating pressure. In case of Drainage water at $100 \mathrm{kPa}$, the emitter clogging percent was (12.24, 21.33 and 70.75\%) for turbo key, long path and pressure compensating, respectively after 181 hours of operating period. With Fertilized water at $100 \mathrm{kPa}$, the clogging percent was (11.38, 19.12 and 34.50\%) for turbo key, long path and pressure compensating, respectively. Increasing the operating pressure led to remove deposits outside the emitter and the clogging percent decreased, as occurred with turbo key emitter. Both of water quality and emitter type play an effective role in maintaining drip irrigation system efficiency for a long time.

Keywords: Emitter clogging percent; pressure compensating- turbo keylong path emitters; irrigation water quality; operating pressure and operating period.

\footnotetext{
${ }^{(1)}$ Professor of Agric. Eng. Dept., Fac. Ag., Menoufia University., Egypt.

${ }^{(2)}$ Eng. of Ag. Eng. Dept. and post graduate student Fac. Ag., Menoufia University., Egypt.
} 


\section{1- INTRODUCTION}

Drip irrigation system is widely spread as it can be used safely for most soil types; beside it has high theoretical application efficiency. The use of drip irrigation has been increased in most crop commodities, especially vegetable and fruit crops, to improve water use efficiency and water supply (Jayapiratha et al., 2010).

Drip irrigation systems are designed to deliver a certain amounts of water and nutrient to the plant. As water becomes more limited in arid and drought prone areas, these systems are used more widely. There are numerous advantages using drip irrigation systems. However, these advantages could be nullified by emitter clogging, which is directly related to the quality of the irrigation water (Dehghanisanij et al., 2005). Using drainage water in drip irrigation system is possible and successful by using the appropriate water treatments. They also showed a slight increase in relative flow over time (Sharaf and Aboamera, 1998).

The clogging of emitters is a major problem encountered in drip irrigation systems, as partial or complete clogging reduces application uniformity. Clogging is closely related to the quality of the water used. Despite the quantity of research reported in literature concerning the quality treatment and distribution uniformity of irrigation water, the problem still remains of accurately foreseeing the clogging risk on the basis of the irrigation water quality and the corresponding effects on emitter flow rate in causing lack of uniformity in the field. Indications can be drawn about the number of emitters to be tested in the field and also the relationships between clogging and emitter position in the lateral (Capra and Scicolone, 1998).

The reasons for emitter clogging can be classified into three types: physical, chemical and biological clogging. Physical clogging is caused by suspended inorganic particles (such as sand, silt, clay and plastics), organic materials (animal residues, snails, etc.), and microbiological debris (algae, protozoa, etc.); physical materials are often combined with bacterial slimes. Chemical problems are due to dissolved solids interacting with each other to form precipitates, such as the precipitation of calcium carbonate in waters rich in calcium and bicarbonates. 
Biological clogging is due to algae, iron slimes and sulphur slimes (Wu et al., 2004).

Other workers (Hills and Tajrishy, 1995) showed that in addition to the presence of biological clogging agents and solute chemistry of water, the severity of clogging depends on the manufacturing quality of the emitters, such as the type of emitter and its dimensions, emitter water flow cross-section area, path length, flow velocity, and pressure compensation.

(Ravina et al., 1992) showed that different types of emitters had different susceptibilities to clogging, but for any particular type of emitter, clogging sensitivity was inversely proportional to the discharge of the emitter. They suggested maintaining turbulent flow in the laterals to prevent sedimentation.

Emitter clogging was affected mainly by emitter type, location along the lateral and the interaction between these two factors. Differences among emitters with larger clogging were only observed at the end of drip line (Duran-Ros et al., 2009).

The discharge rate per emitter is very small and it is usually only one $\mathrm{L} / \mathrm{h}$ $-8 \mathrm{~L} / \mathrm{h}$ (more of one $\mathrm{L} / \mathrm{h}-4 \mathrm{~L} / \mathrm{h}$ ). The width of the flow path of an emitter is much small and it is usually only about $0.6 \mathrm{~mm}-1.3 \mathrm{~mm}$. The drip irrigation system can be easily deteriorated if the emitter is clogged by the pollutants in water. The structure and hydraulic performances of emitters have an important impact on the irrigation uniformity, anticlogging capacity and life-span of the drip irrigation system (Yun-Kai et al., 2005).

The main objective of this study was to evaluate the emitter clogging percent and its changing according to the operating period. The percent of emitter clogging will be stated under three types of irrigation water which are; Nile, Drainage and Fertilized water. This will studied at three types of emitters which are common used in Egypt. They are turbo key; pressure compensating and long path emitters. The operating pressure will be changed and taken four levels which are; 75,100,125 and 150 $\mathrm{kPa}$. 


\section{MATERIALS AND METHODS}

\section{Experimental site and drip irrigation system}

The present work was conducted in the laboratory of Agricultural Engineering Department, Faculty of Agriculture, Menoufia University during 2015. A drip irrigation system was constructed outdoors and was adjusted every irrigation event. The drip irrigation system was fitted by all the required devices that used in measuring both factors and the affected parameters. These devices were: pressure gauge, pressure regulator, flow meter and control valves.

Used drip irrigation system having the possibility of changing both of the studied emitters and the lateral spacing as shown in fig.1. The main pipe made of galvanized iron and was located between tank outlet and pump inlet with inner diameter of $1.5 \mathrm{inch}$. The sub-main line was of

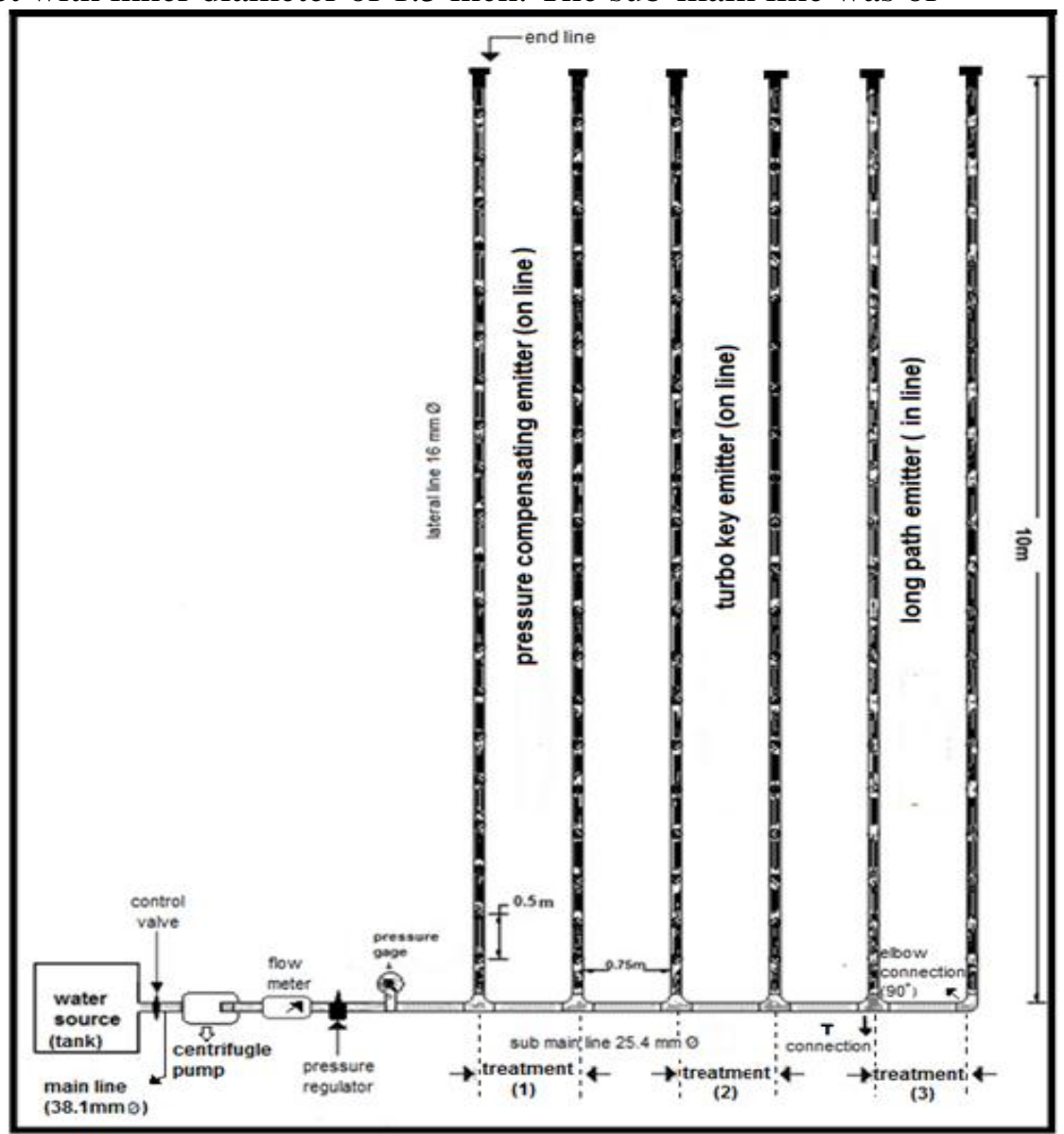

Fig.(1): Plan view of the expeimental drip irrigation system 
Pulley Vinyl Chloride (PVC) with $25.4 \mathrm{~mm}$ diameter, 5m length and connected with flush cap. At the beginning of the submain flow meter, pressure regulator and pressure gage had been fitted carefully. Lateral line was of Pulley Ethylene (PE) with $16 \mathrm{~mm}$ diameter and $10 \mathrm{~m}$ length. The distance between laterals was $0.75 \mathrm{~m}$, and it was $0.5 \mathrm{~m}$ between the emitters. Six laterals were used for each type of irrigation water under each operating pressure and every two laterals having the same emitter. The three tested emitters were:

(a) Turbo-key emitter with nominal flow rate $8 \mathrm{~L} / \mathrm{h}$ and emitter spacing of $0.5 \mathrm{~m}$.

(b) Pressure compensating emitter with nominal flow rate $4 \mathrm{~L} / \mathrm{h}$ and emitter spacing of $0.5 \mathrm{~m}$.

(c) Long path emitter with nominal flow rate $6 \mathrm{~L} / \mathrm{h}$ and emitter spacing of $0.5 \mathrm{~m}$. Fig.(2) represents sectional elevation of each emitter type.

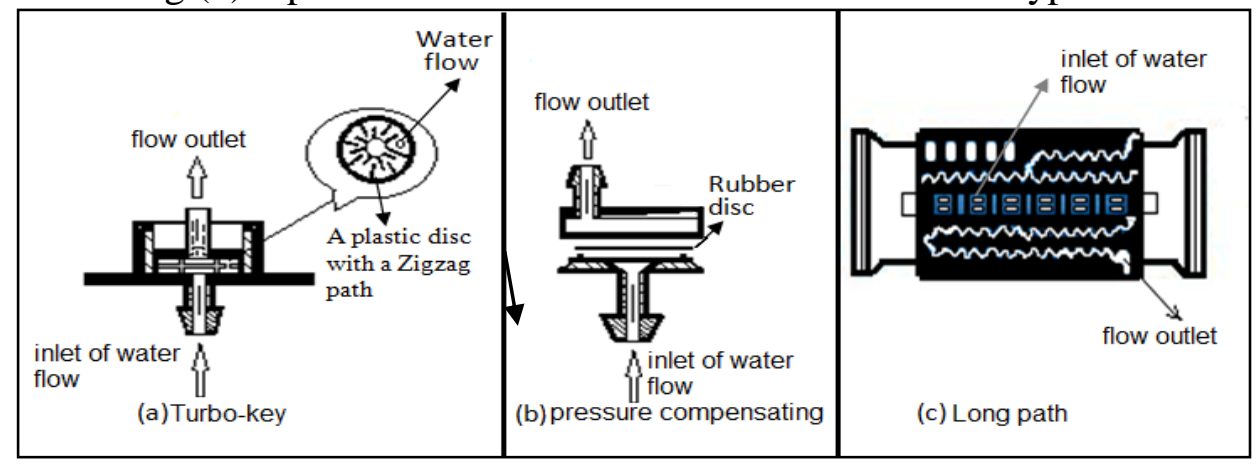

Fig. (2): Sectional elevation of the three types of tested emitters and the direction of water flow in each type

\section{Experimental treatments}

The experimental study concerned with changing both type of irrigation water and emitter type. Three types of irrigation water were tested which were: Drainage water, Nile water and Nile water mixed with fertilizers. Three types of emitters were selected considering that they highly common used almost for all crops. These types were: turbo key, pressure compensating and long path. For each treatment, the system was operated at four levels of the operating pressure which were: 75, 100, 125 and 150 $\mathrm{kPa}$. This procedure was also conducted only for driving emitter discharge pressure relationship for each one of the tested emitters. Each level of the irrigation water includes three treatments and each treatment 
contains two lateral lines. For all the tested treatments, the affected hydraulic parameters were computed with the aim of differentiation between the studied factors. The main hydraulic parameter was the percent of emitter clogging which will be computed according to the average value of emitter discharge for each treatment. For each type of irrigation water the system was operated 4 hours daily and the average value of emitter discharge was measured every two weeks in order to follow the accumulation of clogging for each emitter type at each level of irrigation water.

\section{Source of irrigation water}

Two sources of the used irrigation water were considered, one was from open channel (Nile water) and the other was from general drain (Drainage water). Drainage water was taken directly from drain of KafrElmeselha, Shebin el-Kom, Menoufia, Egypt. Another type of irrigation water was considered when the Nile water mixed by fertilizers with the recommended concentration. Therefore, the used irrigation water type was examined with three levels which were: Drainage water, Nile water and mixed Nile water with fertilizers. The used fertilizers were Nitrogen (N), Phosphorus (P) and Potassium (K) (20-20-20).

Both of Drainage, Nile and Fertilized water were examined for 181 hours. Table (1) represents the chemical analysis of each water type. Analysis of these three types was carried out in the central laboratory of Agriculture Faculty, Menoufia University.

The chemical analysis that presented in Table (1) stated the quality of each water type. It is clear that there was a great difference in all the measured properties between all water types.

Table(1):Chemical analysis of the used Nile, Drainage and Fertilized water

\begin{tabular}{|c|c|c|c|c|c|c|c|c|c|c|c|}
\hline \multirow[b]{2}{*}{$\begin{array}{l}\text { Irrigation } \\
\text { water type }\end{array}$} & \multicolumn{4}{|c|}{ Cataions (meq/L) } & \multicolumn{3}{|c|}{ Anaions } & \multirow{2}{*}{$\begin{array}{c}\text { Total } \\
\text { dissolved } \\
\text { solids } \\
\text { TDS } \\
\text { mg/L }\end{array}$} & \multirow[t]{2}{*}{ PH } & \multirow{2}{*}{$\begin{array}{c}\text { Electrical } \\
\text { conductivity } \\
(\text { EC) } \\
(\mathrm{ds} / \mathrm{m})\end{array}$} & \multirow{2}{*}{\begin{tabular}{|c} 
Sodium \\
adsorption \\
ratio \\
(SAR) \\
$(\%)$
\end{tabular}} \\
\hline & ڤิ & 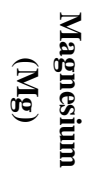 & 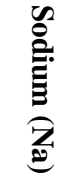 & 页总 & 兽莺 & $\widehat{\varrho} \stackrel{\rho}{=}$ & 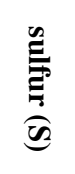 & & & & \\
\hline Nile water & 1.5 & 2.00 & 0.60 & 0.20 & 0.40 & 2.00 & 1.90 & 560 & 7.55 & 0.42 & 0.45 \\
\hline Drainage water & 4.00 & 4.00 & 1.30 & 0.60 & 0.44 & 3.00 & 6.46 & 780 & 7.79 & 1.09 & 0.65 \\
\hline Fertilized water & 1.60 & 2.13 & 0.70 & 1.20 & 0.43 & 2.70 & 2.50 & 580 & 7.68 & 0.47 & 0.52 \\
\hline
\end{tabular}


These differences will have a remarkable effect on emitter clogging percent for each treatment. Each treatment contains two laterals line and each line includes 20 emitters, and divided into three replications. In each replication; catch cans were fixed under each emitter for 5 minutes and the average emitter discharge was computed for each treatment.

\section{Emitter clogging percent}

The volume of water delivered for each selected emitter was collected for 5 minutes to measure the average emitter discharge. At every evaluation period, the obtained data were used to calculate the clogging percent which occurred in each type of irrigation water, and each emitter type. The clogging percent can be obtained from the following Equation:

$$
P_{c l o g}=100\left(1-\frac{q_{a}}{q_{c}}\right)
$$

Where; $\mathrm{q}_{\mathrm{c}}=$ nominal discharge rate for each type of emitter at each level of operating pressure $(\mathrm{L} / \mathrm{h})$; and $\mathrm{q}_{\mathrm{a}}=$ average measured emitter discharge for each treatment $(\mathrm{L} / \mathrm{h})$.

For each level of the examined irrigation water type, the value of clogging percent was remarkably considered from two points of view. The first was calculated the clogging percent for each individual irrigation event. The second focused upon the accumulation of clogging along the total period of irrigation.

\section{RESULTS AND DISCUSSIONS}

\section{Emitter clogging percent with operating pressure}

Fig (3) illustrated the trend of changing the emitter clogging percent due to changing the operating pressure. In general for all the tested emitters and irrigation water types, the value of emitter clogging percent decreased with increasing operating pressure. In all the three levels of water type, the figure also showed that turbo key emitter achieved the lowest value of emitter clogging percent comparing with the other two types. For example, the lowest percent of emitter clogging $(0.57 \%)$ observed with Nile water at $150 \mathrm{kPa}$ of operating pressure when turbokey emitter is used. The highest emitter clogging percent $(8.03 \%)$ observed with drainage water with $75 \mathrm{kPa}$ of operating pressure when pressure compensating emitter is used. Long path emitter gave a moderate value of emitter clogging percent for all water types. The chemical analysis of the Drainage water which presented in Table (1) 
showed that all the chemical properties of this type of water took the greatest values comparing with other types. This in turn caused a higher percent of emitter clogging even after the short operating period. The values of the calculated emitter clogging percent considered acceptable values and did not affect on the emitter uniformity. This was after one hour of the operating period, where the emitters still gave the accepted uniformity coefficient for all the tested types of water.
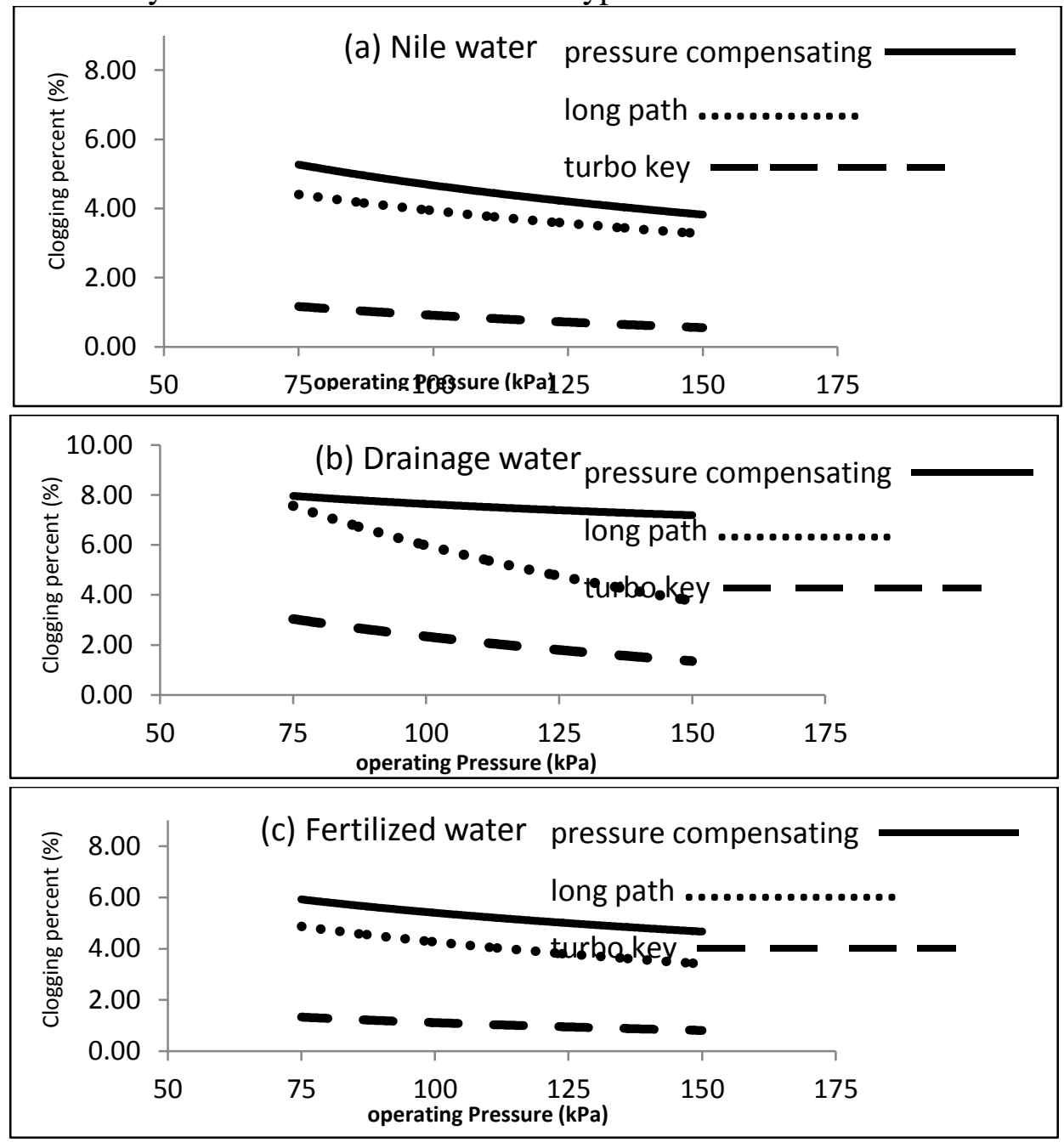

Fig (3): Relationship of emitter clogging percent and operating pressure for the three types of irrigation water after $1 \mathrm{hr}$ of operating period.

Fig (4) represents the changing of emitter clogging percent with operating pressure for all types of irrigation water after $61 \mathrm{hr}$ of operating 
period. It is clear that, at all levels of water quality, the emitter clogging percent decreased with increasing the operating pressure. Normally, the calculated percents of emitter clogging after this period became remarkable due to increasing clogging percent. The highest clogging percent $(27.45 \%)$ was recorded with pressure compensating emitter when Drainage water is used at $75 \mathrm{kPa}$ of operating pressure. The lowest percent $(1.26 \%)$ was observed with turbo key emitter when the Nile water is used. At each emitter, the type of irrigation water which reflexes its quality plays an effective role in the computed value of percent of emitter clogging. The poorest water quality was observed with the Drainage

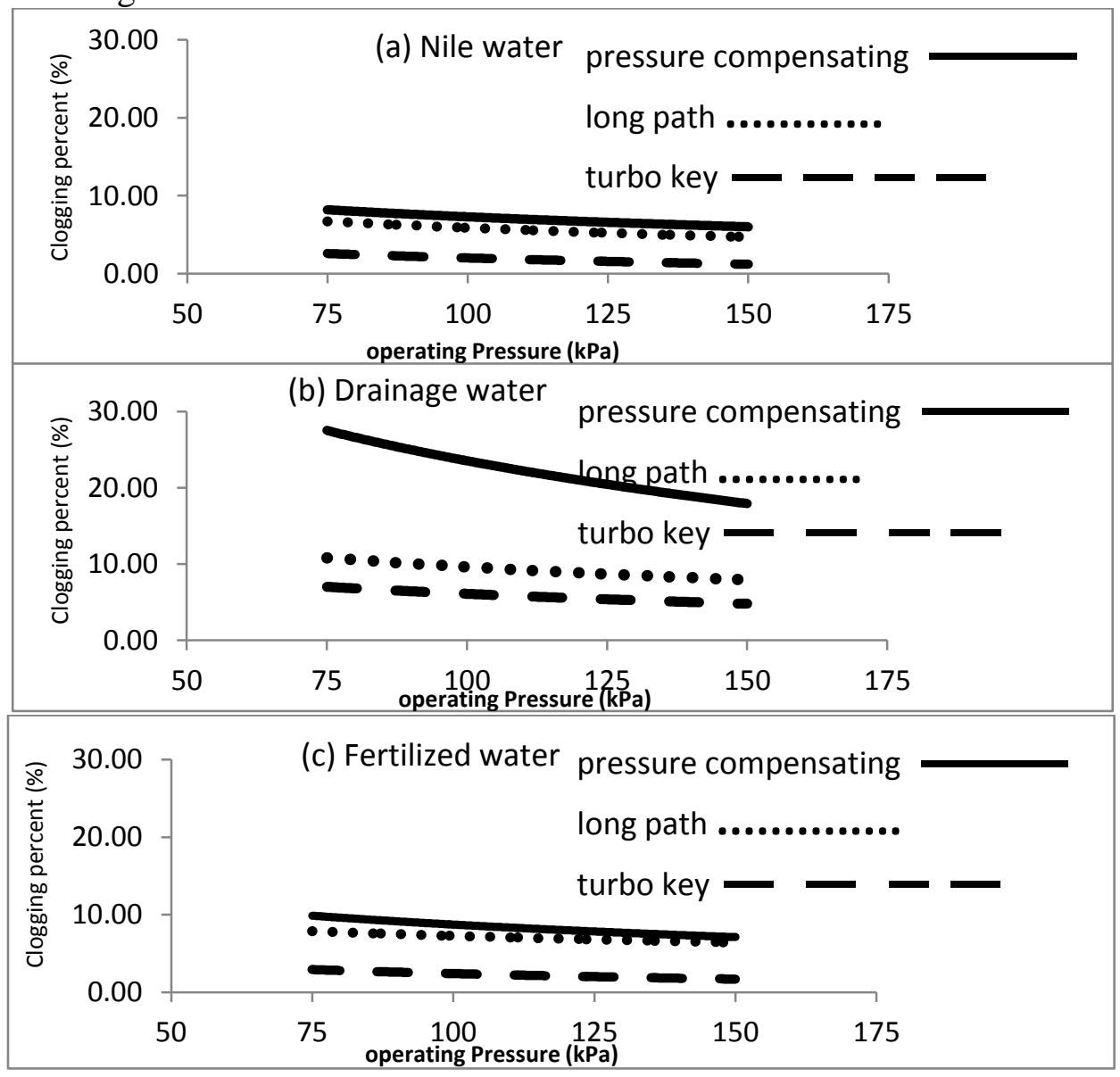

Fig. (4): Percent of emitter clogging with operating pressure after 61 hours of operating period for the irrigation water types 
water and this level of quality effect strongly on the calculated percent of emitter clogging. The calculated percent of clogging were extremely affected by the type of the used emitter. The three types of emitter were differed in structure as presented in fig. (2); hence the emitter clogging percent was varied when comparing between these three types at each level of water type.

With using of drainage water with turbo-key and long path emitters, the clogging percents became closed to each other and were approximately having the same difference at each level of operating pressure. While, with both Fertilized and Nile water, the long path emitter moved near by the pressure compensating emitter. This means that, the long path emitter affected with operating period and its accumulation clogging might be considered.

With the larger operating period the clogging process tend to be more effective after a period of operation 121 hours as shown in Fig.(5). The emitter clogging percents increased continuously with the operating period at each level of operating pressure. At this period the emitter clogging percent reached to $48.09 \%$ with pressure compensating emitter and Drainage water at $75 \mathrm{kPa}$ of operating pressure. This means that a larger part of emitter discharge was lost after 121 hours of operation. While the obtained percents of clogging with the other two types of emitters remained at the allowable value, where this percents ranged between $4.37 \%$ and $14.12 \%$ for turbo-key and long path emitters respectively. In case of pressure compensating emitter, the clogging percents were quite higher with Nile and Fertilized water but became extremely higher with drainage water. The lowest clogging percent with this emitter was $20.10 \%$ with Nile water at $150 \mathrm{kPa}$. While with Fertilized water the highest clogging percent was $32.32 \%$ at $75 \mathrm{kPa}$. These results concluded to exclude the pressure compensating emitter due to its highest values of clogging percents at the three types of water applied. Applications of Drainage water with pressure compensating emitter still the worst case from the point of view of clogging percent. This can be used in interpretation the highest difference of clogging percent between these three types of emitters in case of using Drainage water. As for Nile water and Fertilized water it can be noticed that almost 
the same trend was obtained with the three types of emitters. But after 121 hours of operation the clogging percent increased for all cases comparing with 61 hours of operation. With these percents of emitter clogging the emitters became partially clogged and might be observed carefully for maintenance or replacement with new emitters.

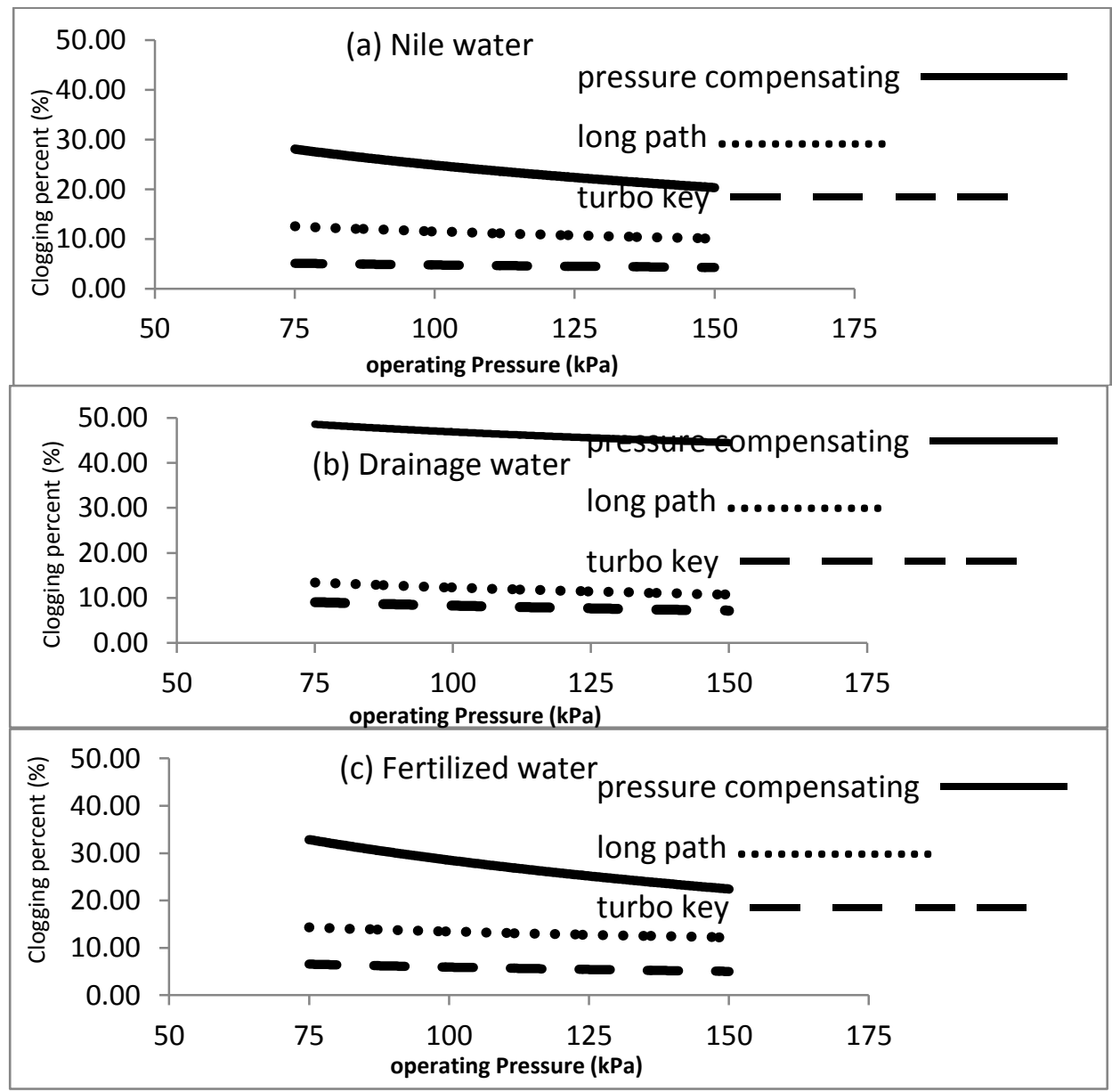

Fig. (5): Percent of emitter clogging with operating pressure after 121 hours of operating period for the three types of irrigation water

Fig.(6) showed that both of turbo key and long path emitter can be used safely with both Drainage and Fertilized water. This was in turn due to approximately the same trend which obtained after 181 hours of operating period. At this period the clogging percent raised greatly specially in case of applying Drainage water. It reached to its highest value $(71.13 \%)$ with pressure compensating emitter at $75 \mathrm{kPa}$ of 
operating pressure. With pressure compensating emitter at all levels of operating pressure, the clogging percent was extremely greater comparing with the other tested emitters. After this operating period (181 hours) the turbo key emitter remained with its lowest value of clogging percent where, it was ranged between $7.59 \%$ and $9.83 \%$ in case of applying Nile water. Normally, the three tested types of emitters can be used at all levels of operating pressure when the Nile water is applied. It also observed the compatibility between turbo key and long path emitters that obtained in all cases. Finally it can be concluded that using irrigation water with low quality, such that the Drainage water, in drip irrigation systems will be safe. This conclusion corresponded to using either turbo key emitter with a discharge of $8 \mathrm{~L} / \mathrm{h}$.

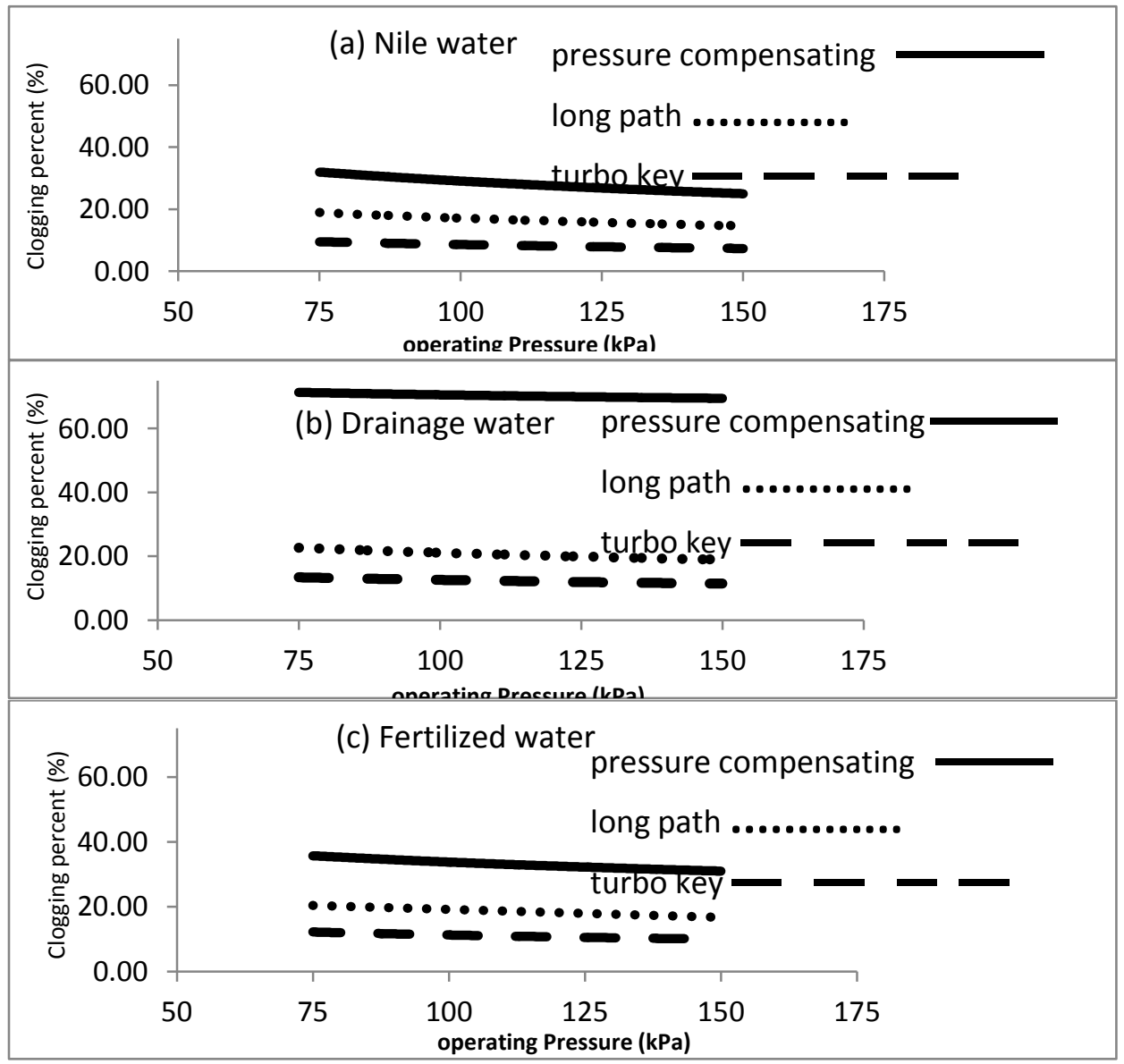

Fig. (6): Percent of emitter clogging with operating pressure after 181 hours of operating period for the three types of irrigation water 
or long path with a discharge of $6 \mathrm{~L} / \mathrm{h}$. But the type of emitter (turbo-key) gave satisfied values of clogging percent when both of Drainage and Fertilized water was used. The clogging percent ranged between 9.89\% and $12.19 \%$ with Fertilized water and between $11.61 \%$ and $13.64 \%$ with Drainage water at all levels of operating pressure. Comparing between turbo key and long path emitters with respect to emitter clogging percent that obtained after 181 hours, the results recommended using turbo key because of its lowest percents that recorded even after 181 hours.

\section{Interaction effect of the studied factors on emitter clogging percent}

A statistical analysis of statistic program of Statistical Package for Social Sciences (SPSS) has been carried out with the aim of driving the interaction effect of the independent studied factors on emitter clogging percent. As mentioned before, the fixed studied factors were emitter type, irrigation water type and operating period. The statistical analysis was conducted only at $100 \mathrm{kPa}$ of operating pressure. Analysis of variance (ANOVA) of the emitter clogging percent presented in Table (2).

In order to drive the interaction effect of operating period, irrigation water quality and emitter type, the $\mathrm{F}_{\text {calculated }}$ was listed in Table (2). The significance was considered based on the difference between the tabulated (F) and calculated (F) at $1 \%$ level of significance. It evidence that the combination of both of operating period, irrigation water quality and emitter type was effected strongly on emitter clogging percent. Table(2): Analysis of variance of the impact of operating period, irrigation water type and emitter type on clogging percent

\begin{tabular}{|c|c|c|c|c|c|}
\hline Source & $\begin{array}{c}\text { S.S (Sum of } \\
\text { Squares) }\end{array}$ & $\begin{array}{c}\text { Degree } \\
\text { of }\end{array}$ & $\begin{array}{c}\text { M.S (Mean } \\
\text { Square) }\end{array}$ & $\mathbf{F}_{\text {cal }}$ & $\mathbf{F}_{\text {tabulated }}$ \\
\hline Operating period & 7206.41 & 3 & 2402.14 & $102709.85^{* *}$ & 4.04 \\
\hline Water type & 1568.90 & 2 & 784.45 & $33541.31^{* *}$ & 4.88 \\
\hline Emitter type & 7056.59 & 2 & 3528.29 & $150861.79^{* *}$ & 4.88 \\
\hline period * water & 544.94 & 6 & 90.82 & $3883.42^{* *}$ & 3.06 \\
\hline period * emitter & 3177.14 & 6 & 529.52 & $22641.23^{* *}$ & 3.06 \\
\hline water * emitter & 1541.70 & 4 & 385.42 & $16479.87^{* *}$ & 3.56 \\
\hline period*water*emitt & 867.07 & 12 & 72.26 & $3089.50^{* *}$ & 2.64 \\
\hline Experimental & 1.68 & 72 & 0.0235 & & \\
\hline Total & 42155.40 & 108 & & & \\
\hline
\end{tabular}

(**): Highly significant at $1 \%$ level of significance. 
This was calculated due to the statistical analysis where the value of $F_{\text {calculated }}$ was highly significant. In addition this interaction of period, irrigation water type and emitter stated that these three main factors might be taken into consideration when the decision of replacement emitters is concerned.

\section{Statistical ranking of the main factors}

The statistical ranking of the studied factors was carried out using (DUNCAN) test. In this test, the essential parameter (emitter clogging percent) was taken with each individual factor with the aim of arranging each level for each studied factor. Therefore, the test was conducted statistically in three faces: (1) clogging percent VS. operating period, (2) clogging percent VS water type and (3) clogging percent VS emitter type.

\section{Emitter clogging percent VS operating period}

Table (3) represents ranking of operating period's levels according to DUNCAN test with respect to the emitter clogging percent. The level of significance $(1 \%)$ was considered in arranging the four levels of operating periods which were; after one hour, after 61 hours, after 121 hours and 181 hours. The obtained results showed that the four levels of operating periods were highly significant. It arranged due to clogging percent statistically as follows; 181 hours $(24.91 \%)^{\text {a }}$ followed by 121 hours $(17.7 \%)^{\mathrm{b}}$ and 61 hour $(8.1 \%)^{\mathrm{c}}$ and one hour $(4.01 \%)^{\mathrm{d}}$ of the operating period. The significance increased with increasing operating period.

Table (3): Ranking of operating period levels according to DUNCAN test with respect to emitter clogging percent

\begin{tabular}{|c|c|c|c|c|c|}
\hline \multirow{2}{*}{$\begin{array}{c}\text { Operating } \\
\text { period }\end{array}$} & $\begin{array}{c}\text { Number of } \\
\text { samples }\end{array}$ & \multicolumn{4}{|c|}{ Homogeneous groups } \\
\cline { 3 - 6 } & 27 & $4.01^{\mathrm{d}}$ & & 3 & 4 \\
\hline after $1 \mathrm{hr}$ & 27 & & $8.10^{\mathrm{c}}$ & & \\
after $61 \mathrm{hr}$ & 27 & & & $17.70^{\mathrm{b}}$ & \\
after121hr & 27 & & & & $24.91^{\mathrm{a}}$ \\
\hline after181hr & & $* *$ & $* *$ & $*_{* *}$ & $* *$ \\
\hline Significance & & & & & \\
\hline
\end{tabular}

(**): Highly significant at $1 \%$ level of significance. 


\section{Emitter clogging percent VS irrigation water type}

The significance of the irrigation water type and its ranking according to DUNCAN test was presented in Table (4). The three types of the irrigation water (Nile, Fertilized and Drainage water) were arranged due to the value of emitter clogging percent. The three water types were highly significant at $1 \%$ level of significance. Drainage water came at the first arrangement where the emitter clogging percent was $(18.97 \%)^{\mathrm{a}}$, the other two types of the irrigation water took the following arrangement where, their values of emitter clogging percent were closed to each other. These values were $(11.9 \%)^{\mathrm{b}}$ and $(10.15 \%)^{\mathrm{c}}$ for Fertilized and Nile water, respectively.

Table (4): Ranking and significance of irrigation water type according to DUNCAN test with respect to emitter clogging percent

\begin{tabular}{|c|c|c|c|c|}
\hline \multirow{2}{*}{ Water type } & Number of & \multicolumn{3}{|c|}{ homogeneous groups } \\
\cline { 3 - 5 } & samples & 1 & 2 & 3 \\
\hline Nile & 36 & $10.1543^{\mathrm{c}}$ & & \\
Fertilized & 36 & & $11.8964^{\mathrm{b}}$ & \\
Drainage & 36 & & & $18.9686^{\mathrm{a}}$ \\
\hline Significance & & ${ }^{* *}$ & ${ }^{* *}$ & \\
\hline
\end{tabular}

(**): Highly significant at $1 \%$ level of significance.

\section{Emitter clogging percent VS emitter type}

Table (5) represents the obtained ranking from DUNCAN test when the emitter type effect on the value of the emitter clogging percent. Pressure compensating emitter took the first place in significance where, the emitter clogging percent $(24.65 \%)^{\mathrm{a}}$ was highly significant at $1 \%$.

Table (5): Ranking and significance of emitter type according to DUNCAN test with respect to emitter clogging percent.

\begin{tabular}{|c|c|c|c|c|}
\hline \multirow{2}{*}{ Emitter } & \multirow{2}{*}{$\begin{array}{c}\text { Number of } \\
\text { samples }\end{array}$} & \multicolumn{3}{|c|}{ homogeneous groups } \\
\cline { 3 - 5 } & 36 & $5.4182^{\mathrm{C}}$ & & \\
\hline turbo key & 36 & & $10.9521^{\mathrm{b}}$ & \\
long path & 36 & & & $24.6490^{\mathrm{a}}$ \\
\hline pressure compensating & & & $* *$ & $* *$ \\
\hline Significance & & $*^{* *}$ & & \\
\hline
\end{tabular}

(**): Highly significant at $1 \%$ level of significance 
The second place in this arrangement was Long path emitter; the emitter clogging percent was highly significant and it achieved $(10.95 \%)^{\mathrm{b}}$ of emitter clogging percent. DUNCAN test recommended Turbo-key emitter due to its highest significant and produced the lowest value of emitter clogging percent, were it recorded $(5.42 \%)^{\mathrm{c}}$.

\section{Statistical marginal means of clogging percent}

The statistical marginal means of clogging percent which derived by the statistical analysis were illustrated in fig.7. The effect of the interaction of irrigation water type, emitter type and operating period was extremely clear. For all combination the highest marginal mean of clogging percent occurred after 181 hours of operating period, and recorded with Drainage water and pressure compensating emitter. The lowest marginal means was observed with the Nile water and Turbo-key emitter after one hour of operating period. Therefore, the statistical analysis recommended the combination of Nile water and Turbo-key emitter to be used also to a period up to 181 hours. This was in turn due to the lower clogging percent which obtained after this period.

\section{General overview and proposed procedures}

Because of emitter clogging percent is the most important problem faced drip irrigation systems, Table (6) summarized the obtained results and presented a proposed solutions for each case. The three solutions that may be taken into consideration are: (a) to accept the value of emitter clogging percent at which the system will be operated safely; (b) to carry out the recommended maintenance before continue operating the system; and (c) to replace the emitters with new. As presented in Table (6), the replacement of emitter might be done in two cases; first using Drainage water with pressure compensating emitter to a period up to 121 hours; the second is the same water and emitter to be operated up to 181 hours. In addition, the maintenance might be conducted for pressure compensating emitter for all water types only after 121 hours and 181 hours of operating period. Turbo-key emitter was operated safely and can be continue working after 181 hours of operating period for all water types. The maintenance can be conducted for Long path emitter only with Drainage water when operated for a period up to 181 hours. 

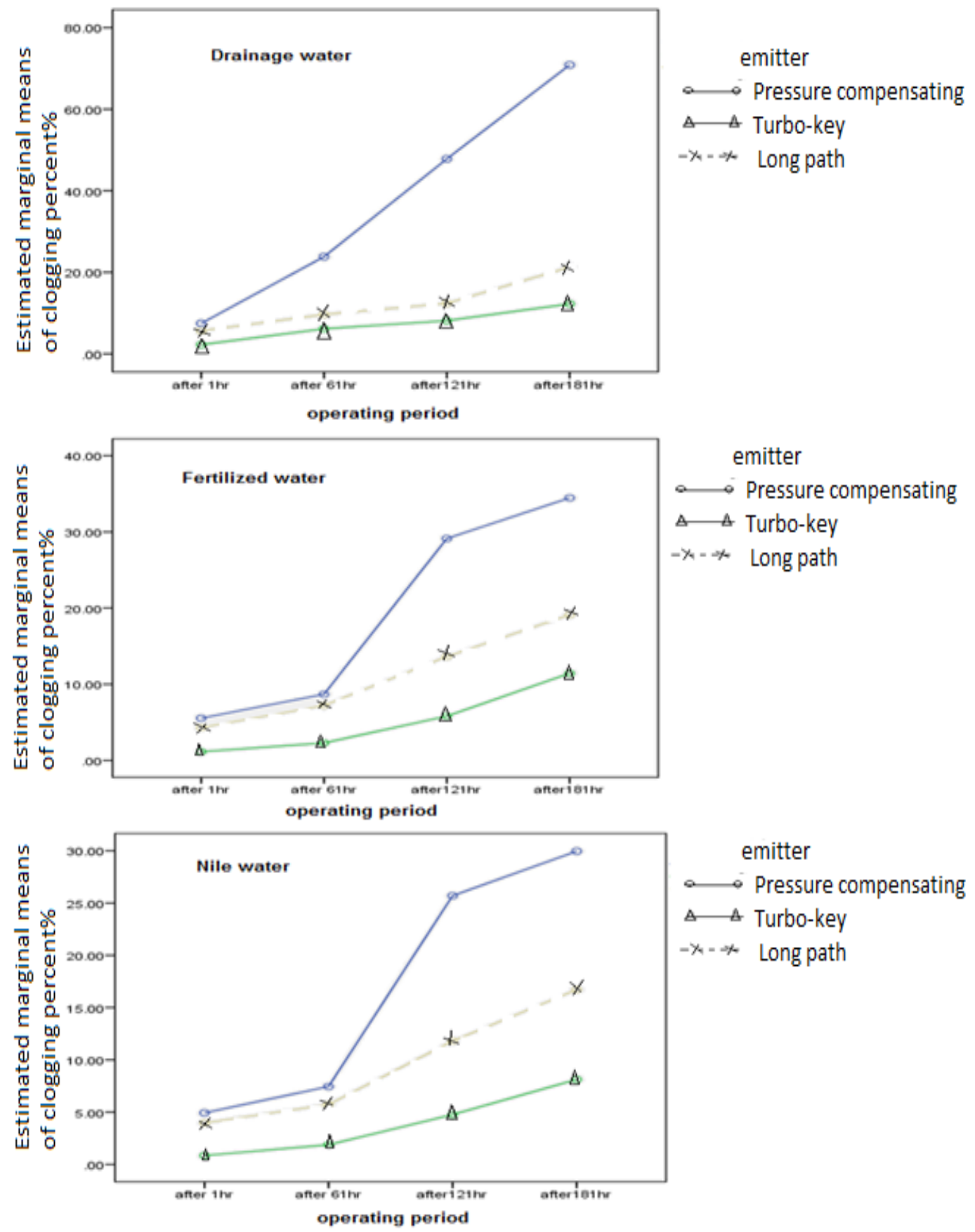

Fig (7): Statistical estimation marginal means of emitter clogging percent 
Table (6): Values of emitter clogging percent for all treatment at $100 \mathrm{kPa}$ of operating pressure and proposed solutions

\begin{tabular}{|c|c|c|c|c|c|c|c|c|c|c|c|c|c|c|}
\hline \multirow{4}{*}{\multicolumn{3}{|c|}{$\begin{array}{l}\text { Emitter } \\
\text { type }\end{array}$}} & \multicolumn{12}{|c|}{ Water type } \\
\hline & & & \multirow{2}{*}{\multicolumn{4}{|c|}{$\begin{array}{l}\text { Nile water } \\
\text { Operating }\end{array}$}} & \multirow{2}{*}{\multicolumn{4}{|c|}{$\begin{array}{c}\text { Drainage water } \\
\text { Operating }\end{array}$}} & \multirow{2}{*}{\multicolumn{4}{|c|}{$\frac{\text { Fertilized water }}{\text { Operating }}$}} \\
\hline & & & & & & & & & & & & & & \\
\hline & & & 1 & 61 & 121 & 181 & 1 & 61 & 121 & 181 & 1 & \begin{tabular}{|l|}
61 \\
\end{tabular} & \begin{tabular}{|l|}
121 \\
\end{tabular} & 181 \\
\hline \multirow{4}{*}{ 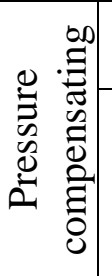 } & \multicolumn{2}{|c|}{$\begin{array}{l}\text { Emitter } \\
\text { clogging }\end{array}$} & 4.93 & 7.50 & 25.70 & 30.00 & 7.50 & 23.75 & 47.81 & 70.75 & 5.50 & 8.75 & 29.13 & 34.50 \\
\hline & \multirow{3}{*}{ 芑 } & $\mathrm{a}$ & $\sqrt{ }$ & $\sqrt{ }$ & $\sqrt{ }$ & $\sqrt{ }$ & $\sqrt{ }$ & $\sqrt{ }$ & & & $\sqrt{ }$ & $\sqrt{ }$ & $\sqrt{ }$ & $\sqrt{ }$ \\
\hline & & $\mathrm{b}$ & & & $\sqrt{ }$ & $\sqrt{ }$ & & $\sqrt{ }$ & $\sqrt{ }$ & $\sqrt{ }$ & & & $\sqrt{ }$ & $\sqrt{ }$ \\
\hline & & c & & & & & & & $\sqrt{ }$ & $\sqrt{ }$ & & & & \\
\hline \multirow{4}{*}{ 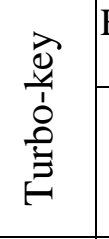 } & \multicolumn{2}{|c|}{$\begin{array}{c}\text { Emitter clogging } \\
\text { percent }(\%)\end{array}$} & 0.88 & 1.88 & 4.76 & 8.12 & 2.25 & 6.14 & 8.12 & 12.24 & 1.13 & 2.25 & 5.81 & 11.38 \\
\hline & \multirow{3}{*}{ 总 } & $\mathrm{a}$ & $\sqrt{ }$ & $\sqrt{ }$ & $\sqrt{ }$ & $\sqrt{ }$ & $\sqrt{ }$ & $\sqrt{ }$ & $\sqrt{ }$ & $\sqrt{ }$ & $\sqrt{ }$ & $\sqrt{ }$ & $\sqrt{ }$ & $\sqrt{ }$ \\
\hline & & $\mathrm{b}$ & & & & & & & & & & & & \\
\hline & & $\mathrm{c}$ & & & & & & & & & & & & \\
\hline \multirow{4}{*}{ 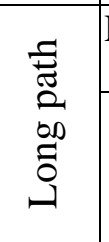 } & \multicolumn{2}{|c|}{$\begin{array}{c}\text { Emitter clogging } \\
\text { percent }(\%)\end{array}$} & 4.00 & 5.73 & 11.83 & 16.72 & 5.67 & 9.67 & 12.38 & 21.33 & 4.33 & 7.22 & 13.67 & 19.12 \\
\hline & \multirow{3}{*}{ 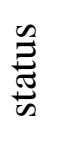 } & $\mathrm{a}$ & $\sqrt{ }$ & $\sqrt{ }$ & $\sqrt{ }$ & $\sqrt{ }$ & $\sqrt{ }$ & $\sqrt{ }$ & $\sqrt{ }$ & $\sqrt{ }$ & $\sqrt{ }$ & $\sqrt{ }$ & $\sqrt{ }$ & $\sqrt{ }$ \\
\hline & & $\mathrm{b}$ & & & & & & & & $\sqrt{ }$ & & & & \\
\hline & & c & & & & & & & & & & & & \\
\hline
\end{tabular}

a: acceptance $\quad$ b: maintenance

c: Replacement

\section{CONCLUSION}

Results indicate that using of pressure compensating emitter demands using high quality water or replacing pressure compensating emitter in this case with turbo-key or long path emitter. In addition to the importance of follow-up and selection the best times to maintain clogged emitter or replace it.

\section{REFERENCES}

Capra, A. and Scicolone, B. (1998). Water Quality and Distribution Uniformity in Drip/Trickle Irrigation Systems. J. Agric. Engng Res. 70, 355-365Article Number: ag980287.

Dehghanisanij, H., Yamamoto, T., Ould, Ahmad B.A., Fujiyama, H. and Miyamoto, K. (2005). The effect of chlorine on emitter clogging induced by algae and protozoa and the performance of drip irrigation. Trans. ASAE, 48 (2): 519-527. 
Duran-Ros, M., Puig-Bargues, J., Arbat, G., Barragan, J. and Cartagena, F., (2009). Effect of filter, emitter and location on clogging when using effluents. Agricultural Water Management, 96, $67-79$.

Hills, D. J. and Tajrishy M. (1995). Treatment requirements of secondary effluent for microirrigation. In microirrigation for a changing world. Proc. $5^{\text {th }}$ Int. microirrigation congress, 887- 892, ed. F.R. Lamm. St. Joseph, Mich.: ASAE.

Jayapiratha V., Thushyanthy M. and Sivakumar S. (2010). Performance evaluation of Okra under drip irrigation system. Asian journal of agricultural research, 4(3): 139-147.

Ravina, I., Paz, E., Sofer, Z., Marcu, A., Shisha, A. and Sagi, G. (1992). Control of emitter clogging in drip irrigation with reclaimed wastewater. Irrigation Sci., 13 (3): 129-139.

Sharaf, G.A., Aboamera, M.A. and Zin El-Abedin, T.K. (1998). Effect of treated drainage water on emitter clogging. Misr.J. Ag.Eng., 15(1): 174-182.

Wu, F., Fan, Y., Li, H., Guo, Z., Li, J. and Li, W. (2004). Clogging of emitter in subsurface drip irrigation system. Trans. CSAE, 20 (1): 80-83 (in Chinese, with English abstract).

Yun-Kai , L., Pei-ling, Y. and Shu-mei, R. (2005). Hydraulic Characterizations of Tortuous Flow in path drip irrigation emitter. Journal of Hydrodynamics Ser.B, 18(4): 449-457.

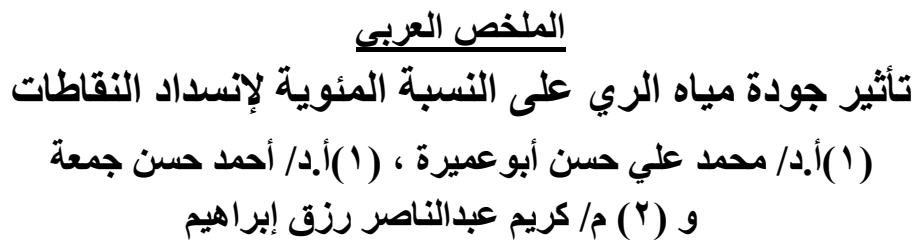

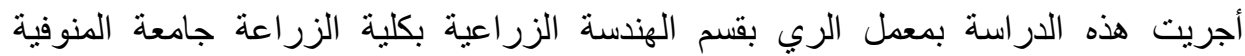

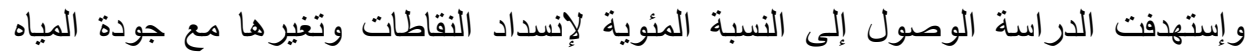

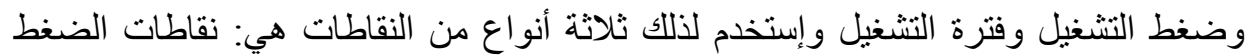
التعويضي Pressure compensating و النقاطات الإضطرابية Turbo-key و النقاطات طويلة المسار long path. 
وأجريت الدراسة عند ثلاثة مستويات لجودة مياه الري هي مياه النيل Nile water ومياه الصرف الزراعي Drainage water ومياه الري المختلطة بالسماد Fertilized water و وعند

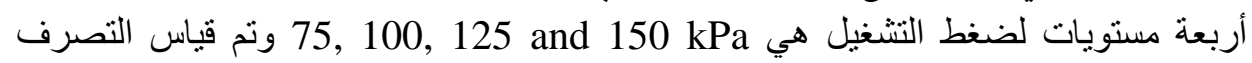

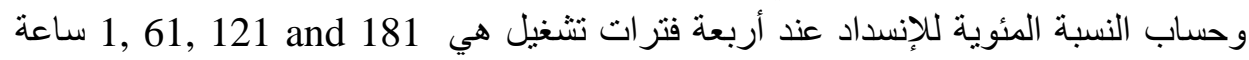

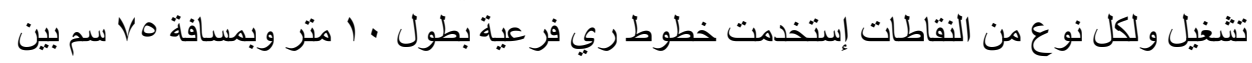

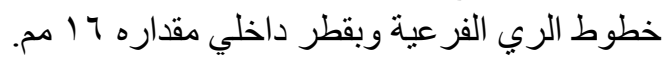
وتوصلت الدراسة إلى النتائج الآتية:

1- تحققت أقل نسبة مئوية لإنسداد النقاطات ومقدار ها (8.12\%) بعد فترة تشغيل 181 ساعة عند إستخدام مياه النيل و النقاطات الإضطر ابية عند ضغط تشغيل ونفيل مقداره 100 . $\mathrm{kPa}$

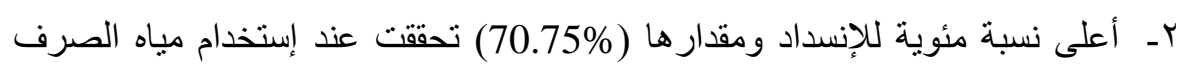

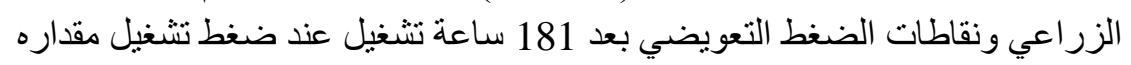
$.100 \mathrm{kPa}$

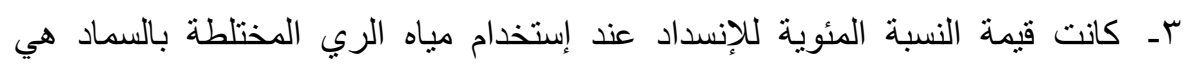

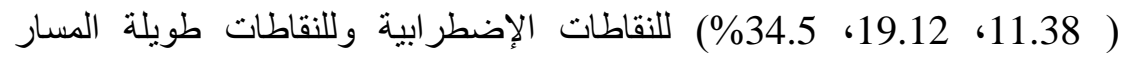

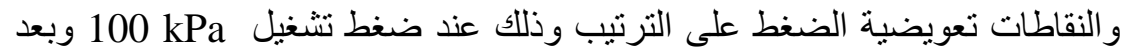
فترة تثغيل مقدار ها 181 ساعة الفئ.

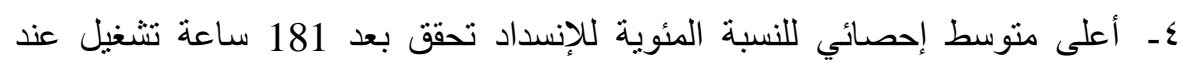

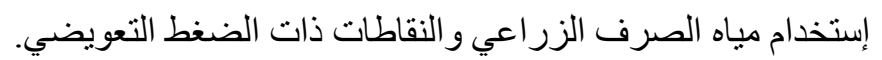

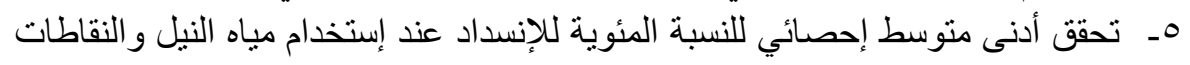

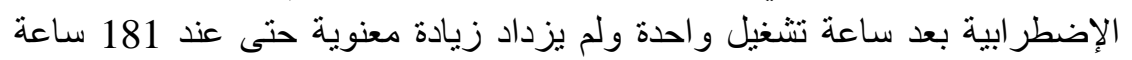
تشغيل. 